\title{
Fahr's Syndrome Discovered at Adulthood Revealing the Pseudohypoparathyroidism
}

\author{
Kawtar Nassar, Saadia Janani \\ Department of Rheumatology, Ibn Rochd University Hospital Center, Medicine and Pharmacy University of Casablanca, \\ Casablanca, Morocco \\ Email: kawtarnassar@yahoo.fr
}

How to cite this paper: Nassar, K. and Janani, S. (2019) Fahr's Syndrome Discovered at Adulthood Revealing the Pseudohypoparathyroidism. Open Journal of Rheumatology and Autoimmune Diseases, 9, 129-133. https://doi.org/10.4236/ojra.2019.94012

Received: November 13, 2019

Accepted: November 25, 2019

Published: November 28, 2019

Copyright (c) 2019 by author(s) and Scientific Research Publishing Inc. This work is licensed under the Creative Commons Attribution International License (CC BY 4.0).

http://creativecommons.org/licenses/by/4.0/

\begin{abstract}
Fahr's syndrome is a rare clinicopathological entity, defined by the presence of intracerebral calcifications not arteriosclerotic, bilateral and symmetric at the level of the basal ganglia, whose main etiology is dysparathyroidism, rarely pseudohypoparathyroidism. Hypocalcemia and hyperphosphatemia despite normal or high levels of parathyroid hormone are the result of resistance to the action of parathyroid hormone. The clinical profile is not specific but dominated by neuropsychiatric symptoms. We report the case of a 30-year-old patient with type pseudohypoparathyroidism revealed one year ago by Fahr's syndrom. The diagnosis made by convulsion history since the age of 5 years resistant to treatment, the disturbance of metabolism disorders, and the presence of intracerebral calcifications. The vitamin D and calcium supplementation have contributed to the stabilization of the disease.
\end{abstract}

\section{Keywords}

Fahr's Syndrome, Pseudohypoparathyroidism, Convulsion, Intracerebral Calcification, Hypocalcemia

\section{Introduction}

Fahr's syndrome is defined by the presence of bilateral and symmetrical basal ganglia calcifications, particularly in patients with dysparathyroidism, and more rarely pseudohypoparathyroidism (PHP), which demonstrates resistance to parathyroid hormone. It is classified according to clinical criteria (multiple hormonal resistance, presence or absence of Albright osteodystrophy), biological or even genetic or epigenetic [1]. The presence of neuropsychic clinical manifestations underlines the interest of the early realization of brain imaging and the search for disorders of phosphocalcic metabolism in order to detect pseudohy- 
poparathyroidism [2]. Patients may have very heterogeneous symptoms, such as seizures, headaches, ataxic or choreic tables, gait disorders, dementia or psychotic pictures. We report a case of Fahr's syndrome that has led to the diagnosis of pseudohypoparathyroidism, discovered in adulthood during hypocalcemic convulsions that have developed since childhood and the presence of calcifications of NGC on magnetic resonance imaging.

\section{Case Representation}

Mr A, aged 30, no profession, the fourth of six siblings, of non-consanguineous parents. In his past history, there were generalized seizures that began at the age of 5 years treated with antiepileptic (phenobarbital) after performing an electroencephalogram having objectified a posterior and irritating dysrhythmia without paroxysmal specific graphoelements. Faced with the persistence of seizures, the patient received carbamazepine since 2008, at a rate of $200 \mathrm{mg}$ and $400 \mathrm{mg} /$ day. The evolution was marked by the spacing of the frequency of symptoms due to an epileptic seizure over eight months. The patient also reported the notion of school failure, complained of excessive shyness and could not take up any professional activity. It was only at the age of 29 that he was referred to our training for diffuse mechanical osteoarthritis and paresthesia in the hands. The neuropsychiatric examination revealed dysphasia with no other abnormalities, including no sign of trousseau and chvostek or extrapyramidal syndrome. There was no dysmorphic syndrome outside of a lunar facies. He weighed $63 \mathrm{~kg}$ for a height of $175.6 \mathrm{~cm}$.

Biological assessment revealed severe hypocalcemia at $55.24 \mathrm{mg} / \mathrm{l}$, albumin at $49 \mathrm{~g} / \mathrm{l}$, and hyperphosphoremia at $54 \mathrm{mg} / \mathrm{l}$. Calciuria was low at $35 \mathrm{mg} / 24 \mathrm{~h}$ with normal phosphaturia at $660 \mathrm{mg} / 24 \mathrm{~h}$. Creatinemia was normal at $10 \mathrm{~g} / \mathrm{l}(\mathrm{DFG}=$ $93 \mathrm{ml} / \mathrm{min}$ ). Circulating parathyroid hormone was normal at $40.51 \mu \mathrm{g} / \mathrm{ml}$. The blood magnesium was $17.8 \mathrm{ng} / \mathrm{l}$. The levels of TSH at $2.73 \mathrm{uIU} / \mathrm{ml}$, growth hormone at $\mathrm{GH}=0.10 \mathrm{ng} / \mathrm{ml}$, were normal to eliminate the other hormonal resistances. The remainder of the balance sheet was without particularity in particular the $25(\mathrm{OH})$ Vit D at $36 \mathrm{ng} / \mathrm{ml}$.

Cerebral magnetic resonance imaging revealed multiple, symmetrical signal abnormalities in favor of sub-cortical calcification and NGC (Figure 1(a) and Figure 1(b)). Standard radiography showed thickening of the skull vault with images of calcifications, 4th and 5th ray bradymetacarpia (Figure 2(a)), hypertransparency of the spine with sandwitch vertebrae (Figure 2(b)).

The diagnosis was the pseudohypoparathyroidism revealed by Fahr's syndrome according to the clinical, biological and radiological manifestations.

The patient was treated urgently with calcium gluconate infusion $(4 \mathrm{~g} /$ day) and then orally (calcium carbonate $3 \mathrm{~g} /$ day) and $1 \mathrm{alfa} \mathrm{OH}$ vitamin D3 (2 ug/day).

He no longer had seizures and his calcemia gradually normalized. Reoriented to the Endocrinology Department and Neurology, he is currently under $2 \mathrm{ug} / \mathrm{day}$ of 1 alfa $\mathrm{OH}$ vitamin D3, $2 \mathrm{~g}$ of oral calcium and carbamazepine $400 \mathrm{mg} /$ day. 


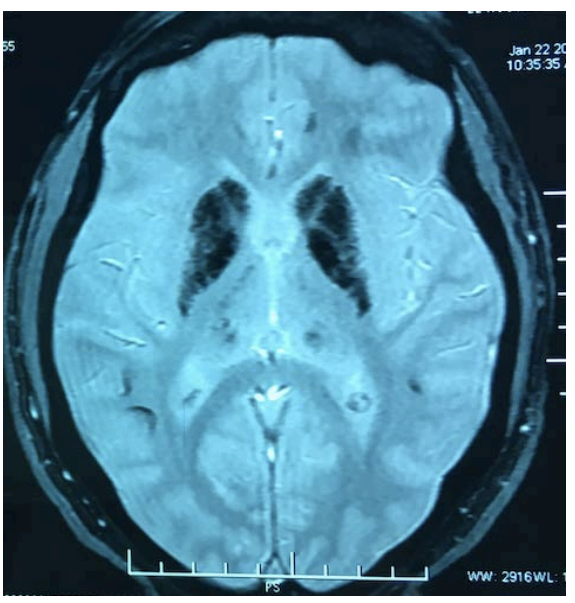

(a)

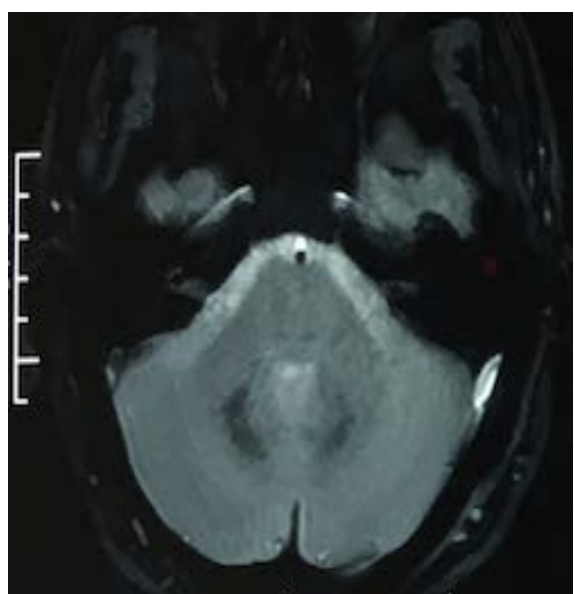

(b)

Figure 1. Axial sections of cerebral MRI: (a) T2 Flair; (b) T2: Hyposignal T2, Flair. The arrows: diffusion with signal vacum of lenticulo thalamic nuclei and caudate bilaterally and symmetrical, with linear T2 signal vacancy under bilateral parietal fronto cortical and cerebellar tent.

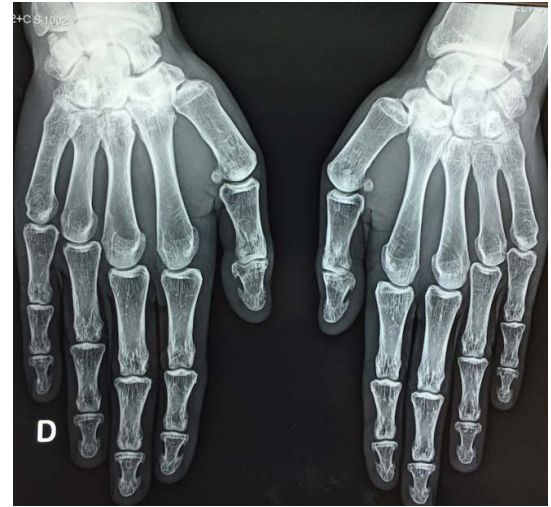

(a)

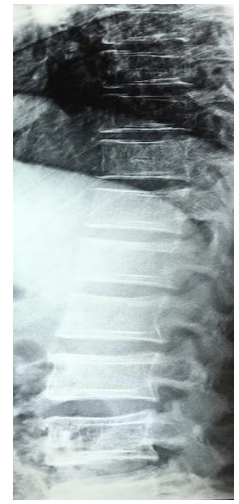

(b)

Figure 2. (a) X-rays of the hands facing: discrete bradymetacarpie of the 4 th and 5 th rays. (B) Dorsal and lumbar spine radiograph in profile: excessive bone transparency and appearance of vertebrae in sandwich.

\section{Discussion}

Fahr's syndrome is a rare clinical anatomical entity, reported for the first time by Theodor Fahr in 1930 [3]. The association of neurological disorders with the presence of bilateral calcifications of NGC (interesting perivascular parenchyma and small vessels) and disturbances of phosphocalcic metabolism leads to the diagnosis. On the other hand, the absence of phosphocalcic abnormalities is rather compatible with Fahr's disease, which is inherited and transmitted in an autosomal dominant fashion.

Fahr's syndrome occurs preferentially in patients with dysparathyroidism, more rarely in a pseudohypoparathyroidism where fewer observations have been reported in the literature [4] [5]. 
The rarity of this association and its late discovery make the originality of our observation.

The pathophysiology of brain calcifications is not fully understood, but hypocalcemia seems to play a role in their constitution. In the cases discovered in adulthood, as in our observation, they are not more voluminous than those described in children. They are not very progressive, asymptomatic or can give rise to neurological complications, such as abnormal movements [6].

The term PHP refers to a group of very rare hereditary metabolic disorders, affecting $1 / 100,000$ to 1 in 10,000,000, characterized by a resistance of target tissues to parathyroid hormone, an essential hormone in phosphocalcic metabolism [7]. The result is hypoparathyroidism (epileptic seizures, hypocalcemia, hyperphosphoremia, infiltrated skin, cataract, dental dysgenesis) paradoxically with a high or normal parathyroid hormone [1].

The two main subtypes of PHP are: Type Ia is linked to a mutation of the GNAS gene and is accompanied by subcutaneous calcification, dysmorphism described by Albright and other hormonal resistances (TSH, GHRH, luteinizing hormones).

Type Ib results from a lack of methylation on the maternal allele of a differential methylation region upstream of GNAS. It corresponds to isolated resistance to PTH, sporadic or familial. The action of the hormone on the bone remains active, which can lead to an increase in bone remodeling, explaining in our patient the radiological appearance of the vertebrae sandwiched [8]. In our observation, the only arguments in favor of a PHP type Ia were the lunar facies and the bradymetacarpie which remains discreet. On the other hand, the patient was not obese; there was no mental retardation or stature, no subcutaneous calcifications, and no other hormonal resistance, which is consistent with a PHP Ib. A molecular genetic study will allow confirming the diagnosis.

The treatment of PHP is based on calcium supplementation and vitamin D (1 alpha or $1.25 \mathrm{OH} 2$ vitamin D3) with regular monitoring of plasma and urinary calcium [9]. The combination of antiepileptic treatment with vitamin and calcium supplementation has improved the symptoms without any other seizure.

\section{Conclusion}

Our observation reports the association of two rare affections: Fahr's syndrome and pseudohypoparathyroidism. The rarity of this association and its late discovery after several years of seizures make the originality of our observation. It emphasizes the importance, in the presence of neurological signs, of investigating disturbances of phosphocalcic metabolism, the determination of PTH and the search for intracerebral calcifications, especially in patients with Fahr's syndrome. The correction of metabolic disorders and the choice of a suitable neurological treatment make it possible to improve the symptoms.

\section{Conflicts of Interest}

The authors declare no conflicts of interest regarding the publication of this paper. 


\section{References}

[1] Otheman, Y., Khalloufi, H., Benhima, I. and Ouanass A. (2011) Neuropsychiatric Manifestations Revealing Pseudohypoparathyroidism with Fahr's Syndrome. Encephalon, 37, 54-58. https://doi.org/10.1016/j.encep.2010.03.001

[2] Mantovani, G. (2011) Clinical Review: Pseudohypoparathyroidism: Diagnosis and Treatment. The Journal of Clinical Endocrinology \& Metabolism, 96, 3020-3030. https://doi.org/10.1210/jc.2011-1048

[3] Chevalier, D., Marie, L., Tillon, J. and Lévesque, H. (2005) A Cause of Intracerebral Calcifications Not to Be Ignored: The Fahr Syndrome. La Revue de Médecine Interne, 26, 668-670. https://doi.org/10.1016/j.revmed.2005.03.013

[4] Kahloul, N., Chaari, W., Boughamoura, L., Charfeddine, L., Khammeri, S. and Amri, F. (2009) Pseudohypoparathyroidism Revealed by Fahr Syndrome. Pediatrics Archives, 16, 444-448. https://doi.org/10.1016/j.arcped.2009.02.017

[5] Linglart, A. (2007) Consequences of PTH Resistance on Adult Bone. Pediatrics Archives, 14, 546-548. https://doi.org/10.1016/j.arcped.2007.02.033

[6] Faissolle, P., Wagner-Mahler, K., Mas, J.-C., Moreigne, M., Khalfi, A., Leonetti, V., Silvy, M., Barlier, A. and Giudicelli, H. (2008) A Cause of Intracerebral Calcifications to Be Known: Pseudohypoparathyroidism Type Ib. Pediatric Archives, 15, 1433-1436. https://doi.org/10.1016/j.arcped.2008.06.016

[7] Chaabene, A., Kamoun, F., Charfi, N., et al. (2006) Hypocalcemic Epileptic Seizures: Study of Seven Cases. Epilepsies, 18, 149-154.

[8] Elli, F.M., Sanctis, L., Peverelli, E., Bordogna, P., Pivetta, B., Miolo, G., et al. (2014) Autosomal Dominant Pseudohypoparathyroidism Type Ib: A Novel Inherited Deletion Ablating STX16 Causes Loss of Imprinting at the A/B DMR. The Journal of Clinical Endocrinology \& Metabolism, 99, E724-E728.

https://doi.org/10.1210/jc.2013-3704

[9] Bastepe, M. and Juppner, H. (2005) GNAS Locus and Pseudohypoparathyroidism. Hormone Research, 63, 65-74. https://doi.org/10.1159/000083895 